\title{
Biology and the moral paradoxes
}

\author{
Richard D. Alexander \\ Museum of Zoology, Insect Division, University of Michigan, Ann Arbor, MI 48109, USA
}

\begin{abstract}
Considerations from biology suggest (1) that human interests can be generalized as reproductive, involving activities by individuals that tend to promote the survival of their individualized sets of genes; (2) that ethical, moral and legal questions arise out of conflicts of interest that exist because of our history of genetic differences; (3) that human behavior probably always involves egoistic tendencies and moral inconsistency; (4) that the stages of moral development described by social scientists correspond to the patterns of life effort discussed by biologists; $(5)$ that the idealized moral systems of philosophy and religion have been developed as models that are promoted in others but not (or more than) in one's self; and (6) that what are usually seen as the closest approaches to these idealized models are the sources of our most severe problems because they involve between-group competition and strife.
\end{abstract}

Ethical, moral and legal questions arise out of conflicts of interest among human individuals and groups. Although this assertion seems to be accepted universally, those who write on ethics, morality and law rarely emphasize it (Pound, 1941; Perry, 1954; Kelsen, 1957, represent the exceptions). Evidently, no student of human behavior has undertaken the obvious challenge of explicitly identifying human interests and quantifying their conflicts. Equity theory from psychology, network and exchange theory from sociology and anthropology, and theories of interest from law, political science and economics are partial attempts. These theories, however, are all restricted to a superficial level, involving only reciprocal transfers of good or beneficient acts. They neither identify the ultimate significance of goods and beneficient acts, nor deal satisfactorily with the all-important class of interactions that frustrated equity theorists have termed 'deep and intimate' (Walster, Walster \& Berscheid, 1978). In other words, these theories provide no means of defining human interests in a general or complete sense, therefore, no means of dealing generally with the intensities and directions of individual efforts (see Alexander, 1979, and references therein).

A theory of interests is a theory of lifetimes: what they are about and how their goals are achieved. A growing body of information and theory from biology now provides a reasonable and testable answer: lifetimes have been molded by natural selection to yield the greatest likelihood of survival of the individual's genetic materials. This likelihood is maximized by success in reproduction, which includes producing offspring, and assisting both descendant and non-descendant relatives. The 'deep and intimate' interactions causing difficulty to equity theorists are actually those most directly involving reproduction-those occurring between mates, potential mates and relatives. The currencies that mold the proximate mechanisms of altruism in these interactions are genetic, not a matter of returned goods or services, and this is the reason the payoffs have not been apparent to investigators 
outside biology. Even the investments and returns of reciprocity (exchange, equity) are ultimately comprehensible only in terms of their eventual effects on the 'deep and intimate' interactions of mates and relatives. Included are wealth, status, good will and innumerable other items.

Biologists divide lifetimes into somatic and reproductive effort: use of calories and taking of risks in (1) building the body or soma (= amassing resources) and (2) using the soma to reproduce (= redistributing resources in the interests of one's own genetic materials). Reproductive effort is in turn divisible into mating effort (on behalf of gametes), parental effort (on behalf of offspring) and extraparental nepotistic effort (on behalf of all relatives other than offspring). There are good reasons for supposing that normal lifetimes include no other kind of effort (Alexander, 1979).

I would regard the central paradoxes of moral philosophy to be those of (1) the incompatibility of egoism and utilitarianism (seeking the greatest benefits to one's self versus seeking some version of the greatest benefits to the greatest number) and (2) the associated problem of duality in human nature. These paradoxes have been developed and discussed in many forms, but always independently of the current biological view of interests and lifetimes. I shall argue that they remain paradoxes not because of some inherent irresolvability but because those concerned with them have not adequately discussed the costs and benefits of either egoism or altruism. Kalin (1968), for example, speaks of 'winning' and 'coming out on top', and Frankena $(1973,1981)$ of getting the best score', but neither describes the actual currency involved. Some authors speak of survival, but it is unlikely that humans or any other organism have evolved to survive (Alexander, 1979, 1982b), and it is easy to show that they all do things that reduce their likelihood of survival. Essentially all authors consider pleasure or happiness as reward (benefit) and pain and suffering as punishment (cost), but none can explain in egoistic terms either the voluntary acceptance of pain or the pleasure of helping others. Because the indisputable prevalence of egoistic behavior eliminates any likelihood of a purely altruistic or utilitarian society, except as an unattained (and as yet unexplained) pursuit or ideal, the problem of duality, and of moral inconsistency as normal behavior, persists.

Biological theories of interests and lifetimes have the power to resolve these paradoxes, at least in terms of the natural history of moral systems (the 'why' of behavior in respect to morality). Thus, an organism whose interests are in its own genetic survival must first develop a soma (be a wholly or largely egoistic juvenile), then reproduce (show the 'altruism' of parenthood and nepotism) while maintaining the soma by which it continues to reproduce (thus retaining egoistic tendencies during adulthood). Direct and indirect reciprocity (Alexander, 1979) are distinctive human overlays that add to the complexity, but they create no special problems. They may be seen as indirect somatic or nepotistic efforts routed through pseudo- or temporarily-altruistic investments in the welfare of others who are expected to reciprocate with interest.

The stages of moral development in the individual, as interpreted by Kohlberg (1981) and others, are remarkably supportive of this biological view. Represented, first, is a purely somatic (selfish, 'amoral') stage. This is followed by the introduction of reciprocity through a system of rewards and punishment, usually by the parent. The individual gradually foregoes immediate rewards in favor, I would argue, of larger later ones (reciprocity). Acceptable rewards may be both increasingly later and increasingly less direct (in the senses of involving diverse currencies, and of coming from society at large rather than the person or persons directly involved in the original social act). Eventually the individual also begins to forego personal (somatic) rewards in favor of unreciprocated rewards to others (nepotism). And he becomes increasingly able to assess the profitability of social acts without outside help. 
From these arguments about interests it follows that conflicts of interest arise out of the history of genetic differences. This hypothesis is strongly supported by the absence of observed conflicts among non-human individuals in clones and other cases of long-standing genetic identity, and by the general diminution of altruism with decreasing relatedness within human societies the world over. It explains human individuality, and bears upon powerful human issues, such as what Wallace called the impossibility, despite all the labor of God, Freud and the Devil, of one man fully understanding another, or the loneliness of existence' which he regarded as 'a pan-human theme'. It explains the unique co-operativeness of unrelated pairs pledged to lifetime monogamy, and of genetically different workers in the colonies of social wasps, bees, ants and termites. In both cases the genetically different individuals involved share interests because they reproduce through the same third parties: the offspring produced jointly by the monogamous pair and the siblings of worker insects produced by their common mother. It is significant that Kohlberg's final stage of moral development is that in which the individual has learned for himself how best to assess his personal costs and benefits in following (and using) whatever social rules prevail.

Viewing humans and their moral behavior in terms of natural selection provides stark and dramatic answers to some serious and very general questions: the incompleteness of justice; the persistence of conflicts of interest; the failure of idealized moral systems; and the absence of universal happiness and satisfaction. Part of the answers lie in the relative nature of success in evolutionary terms:

In natural selection the likelihood of a genetic element persisting depends entirely on its rate of change in frequency in relation to its alternatives; changes in absolute numbers are irrelevant. Among the attributes of living creatures, whatever can be shown to have resulted from the action of natural selection may be expected to bear this same relationship to its alternatives. Thus, we should not be surprised to discover that the behavioral striving of individual humans during history has been explicitly formed in terms of relative success in reproductive competition, that justice is necessarily incomplete, that happiness is not easily made universal, and that ethical questions continue to plague us, and can even become more severe when everything else seems to be going well (Alexander, 1979:240).

I stress that our interests are not individual because of genetic differences per se, or current genetic differences, because such information has never been directly available to humans. Relatives are known through circumstantial evidence, and only recently have geneticists learned what the average relatedness actually is for relatives whose learned assumptions about relatedness from genealogical connections and kinds of social interactions are nevertheless usually correct. The individualized genetic constitutions of the successions of our ancestors caused natural selection to save and mold proximate mechanisms whereby appropriate efforts could be mounted by individuals in each successive generation to realize their separate and individualized interests. We learn who our relatives and friends are, and how to treat them; but our learning responses are themselves evolved, and often very specific and channeled.

The hypothesis that conflicts of interest derive from the history of genetic differences also generates new and sometimes startling questions: What are the benefits of the group to the selfishly reproducing individual? Why does one kind of ultrasocial group (eusocial insects) achieve its greatest numbers and unity (up to 22 million) as a single nuclear family in which one individual does all of the reproduction while the other (humans) achieves its greatest numbers and unity (now approaching one billion in China) by leveling the reproductive success and opportunities of its members (through socially-imposed monogamy, graduated income taxes, gradations of negative correlations of government support with family size, restrictions on 'free' enterprise etc)? How do these questions relate to the morality of individuals and the idealized moral systems discussed by moral philosophers? 
The altruism of human nepotism and reciprocity is discriminative: Different relatives, and relatives of different needs, are distinguished. Friends are treated individually. As yet, no evidence of truly indiscriminate, species- or population-wide altruism has been reported for any organism, and there is no undisputed evidence for unlearned recognition of relatives in any species (Alexander, 1982a). These facts are crucial to understanding moral paradoxes and the rise of moral systems. Indiscriminate altruism requires no special proximate mechanisms-no social learning. I would venture that without genetic individuality, and the consequent discriminative altruism in nepotism and reciprocity, social learning would have remained simple, and human society as we know it could not have evolved. The very concepts of ethical, moral and legal would be unknown.

To think of humans existing without conflicts of interest is to assume situations involving or mimicking group selection, in a way explicitly opposing the notion of individuals striving to maximize their separate reproductive successes. It seems to me that this is the ideal state of morality postulated by philosophers and social scientists. If so, perhaps biology gives us the reason for understanding interpretations such as that of Perry (1954: 100).

Morality is like a cultivated field in the midst of the desert. It is a partial and precarious conquest. Ground that is conquered has to be protected against the resurgence of original divisive forces. The moralized life is never immune against demoralization. At the same time that morality gains ground in one direction it may lose ground in another. Changes in the natural and historical environment and the development of man himself are perpetually introducing new factors and requiring a moral reorganization to embrace them. In the last analysis all depends on the energy, perseverance, and perpetual vigilance of the human person.

Numerous philosophers have suggested that morality, at least as expressed in the behavior of individuals, is in fact only an ideal, or a pursuit, and not something that is actually realized. This idea seems consistent with the approach from evolutionary biology that I have been describing. Thus, it is common, if not universal, to regard morality in the behavior of an individual as consisting of a kind of altruism that yields the altruist less than he gives. In a utilitarian system (defining utilitarianism as promoting the greatest good to the greatest number) morality would not always require that complete and indiscriminate altruism cause individual losses. This would not, for example, be the case when the interests of the group and the interests of the individuals comprising the group are the same. Such a confluence of interests would happen each time the group was threatened externally in such fashion that complete co-operation by its members would be necessary to dissipate the threat, and when failure of the group to dissipate the threat would more severely penalize any remaining individuals than would the use of all the individual's effort to (successfully) support them (this is the true, but in these times of nuclear threats forgotten, meaning of the term 'national security'). In other circumstances, as when some competitiveness has a likelihood of benefiting individuals in the group (i.e. the individuals' interests are not all completely tied up in the survival of the group or its success in dissipating some external threat), morality of an ideal sort would require the kind of genetic altruism, unlikely in evolutionary terms, in which the altruist truly gets back less than he gives. Of course, if an external threat came from another group of humans, the definition of morality as indiscriminate altruism would again be in jeopardy.

Reflecting on these circumstances, we see that if approaches to morality are expressed consistently, and to the degree usually achieved in society, because there is continual pressure to bring about a condition of morality, this pressure is likely to be applied by each individual so as to cause his neighbors, if possible, to be a little more moral than himself. To say it another way, it would be to the advantage of each individual that other individuals in his society-especially those not closely related to him-actually achieve the ideal of 
completely moral behavior. Any ideally moral person would incidentally 'help' every other person in the society, however slightly, to achieve the goals that evolutionists believe have driven evolution by natural selection, because he would hurt himself (a competitor) by dispensing his beneficence indiscriminately. Accordingly, one might expect that every individual in a society would gain from exerting at least a little effort toward encouraging other individuals to be a little more moral (altruistic) than they otherwise might have been. Among the many ways of furthering this aim is included the setting up of an idealized model of morality and the encouragement of everyone (else) to become like that. One way of promoting this outcome is to designate as heroes (i.e. as appropriate targets for special rewards) those who most closely approach the ideal moral condition. This line of reasoning predicts that sainthood will be awarded to individuals who spend their lives on explicitly antireproductive behavior. The prevalence among saints of asceticism, self-denial, isolation from relatives, devotion to the welfare of strangers, and otherwise indiscriminate tendencies to be altruistic supports this hypothesis. So does the fact that sainthood is generally awarded (long) after the death of the awardee.

So we are provided with the general hypothesis that the concept of morality, and the establishment of systems promoting ideal moralism, at least appear to have as their aim the support of the goals of society as a whole. For this reason, within society, each and every individual may be expected to promote in his associates tendencies to be moral. Because of continuing possibilities of differential success within groups, though, we can also understand that each and every individual may also be expected to promote a slightly greater degree of 'morality' (altruism) in his neighbor than in himself. And we can understand why the idealized morality of the philosophers is never a reality in society as a whole, and occurs only as an accident, a manipulation or in special circumstances.

The question may be raised, why anyone should be susceptible to being manipulated unduly far in the direction of morality, given that we have been subjected to such manipulations for so long? Why, in other words, should moralizing ever be effective?

I think there are at least four contributing factors. First, the degrees of morality that are actually reproductively appropriate will vary dramatically as societies move between periods of extreme danger and relative security, making it difficult to know how to behave. When will a specified degree of failure to accede to exhortations to be altruistic cost more than it yields, because of (1) failure of the group on which one depends for success, or (2) responses within the group to one's failure to be altruistic?

Second, individuals may be expected to take advantage of the dramatic shifts in most profitable degrees of altruism to deceive others about costs or dangers so as to induce in them unduly altruistic behavior. It is obvious that aspiring leaders often use such deception to promote their own leadership, as an antidote to the supposed threat and as a promoter of unity.

Third, we may expect that the individuals in a society such as we have been describing will evolve to deceive others about the degree of altruism they themselves are exhibiting: Everyone will wish to appear more altruistic than he is. There are two reasons: This appearance, if credible, is more likely to lead to direct social rewards than its alternatives. It is also more likely to encourage others to be more altruistic. If one's associates are altruistic, then he can afford to be more altruistic than if they were not. We may expect everyone to be concerned that everyone else appear altruistic so that people in general will feel comfortable with a higher degree of altruism than would otherwise be the case.

Fourth, if kin recognition is learned (Alexander, 1979, 1982a), mistakes are likely in this context, and one may insinuate himself into the role of relative so as to receive inappropriate nepotism, or even to pretend to be nepotistically altruistic so as to receive the appropriate altruistic responses. 
Playing upon the tendency of everyone to strive to appear more altruistic than one's self, and using the other ploys just described, may produce a considerable amount of successful social manipulation. These various factors seem to be the elements necessary to produce and maintain what we commonly call moral systems, and moral behavior in individuals. They represent the means for resolving the philosophers' paradoxes with respect to morality, and for understanding why moral systems have always fallen short of our ideals, and why we establish and maintain such ideals. If accurate, these arguments may also clarify the routes by which we can most closely approach what are seen as idealized moral systems, and perhaps most confidently avert moral disasters.

The introduction of indirect reciprocity, whereby society as a whole or some large part of it provides the reward for altruism and the punishment for selfishness, simultaneously served both society and the individuals comprising it, and provided the vehicle for socially manipulating individuals to levels and kinds of altruism detrimental to them (or their reproductive success). It is somewhat paradoxical that the tendencies and pressures in the direction of idealized moral systems should serve everyone up to a point, but then be transformed by the same forces that molded them into manipulations of the behavior of individuals that are explicitly against their interests and in the interests of those ostensibly promoting everyone's interests by promoting trends toward morality in the system.

The concept of a single just God for all people, however it is believed to have originated, implies social unity. I would regard this concept as one representation of an idealized moral system arising out of religion; and it is just as difficult to follow as those generated from moral philosophy. It is not trivial that the concept of a single God for all people differs from that of a 'tribal' God looking out for the interests of only one group or society. Adhering to this concept requires denial of practices like slavery, caste systems and other within-group discrimination. Despite its prominence and use during times when groups are threatened externally, the concept in some sense fails whenever such external threats involve (or are) other groups of people. This failure is, of course, denied by the invention of anti-Gods, or Devils, and the ascription of others' motivations to their control. As a US Christian picketing over the arrival of some Russians put it, 'I could love them if they were my enemies, but they are the enemies of God'!

The concept of God also implies continuity of social unity-a long-lasting, intergenerational social contract. If nepotism is our evolved function, then God (in the sense of vox populi, vox Dei) really can guarantee a reward in Heaven', or after our individual deaths-or a kind of 'everlasting life' (for our genetic materials)-as a reward for moral behavior during life. This guarantee is in the form of a renewable contract in reciprocity which occurs when those who remain after our death use our own life of 'morality' to judge our children (and other relatives who remain) as suitable risks to continue receiving (and giving, and receiving and giving, and receiving and giving ...) the benefits of social reciprocity. The guarantee actually exists because, unless those in a position to honor it do so for us, the same possibility will not exist for them. The ceremonies associated with death, and the reverence given to the dead, are surely, in part, ritually related to this guarantee.

If morality tends to mimic the effects of group selection, if moralizing seeks to promote this mimicry, and if tendencies for people to be altruistic are self-reinforcing within societies, then it is not remarkable that sincere, knowledgeable and well-meaning people sometimes resent the arguments that natural selection is not powerful at group levels, and that humans, as individuals, have evolved to be interested in furthering their own reproduction. Such persons may well believe (or sense) that publicizing or stressing such arguments, even if they are correct, will diminish altruism and morality by providing an anti-moral model. The indications that humans have regarded moral models as extremely important in achieving societal 
goals cause such a belief to be completely understandable. Nevertheless, this attitude runs counter to the goal of diminishing human problems through improving self-knowledge.

Our truly serious problems of morality and law stem, not from the behavior of individuals, but from the behavior of groups that may show most dramatically within themselves the indiscriminate altruism that represents approaches to the idealized morality of philosophy and religion. Indeed, loyalty and patriotism are revered as the highest forms of morality and virtue within groups. But this same level and kind of within-group 'morality' has also created our most devastating problems-those involving intergroup conflict-that we must somehow supercede. What we seek, when we think of world peace and world law, has no precedent in the history of life, not to say that of humankind. There seems to be no evidence that humans or any other organism have achieved the species-wide indiscriminate altruism represented in the idealized moral models of philosophy and religion.

I offer only one conclusion in this brief and perhaps unsettling essay: that, in the effort to solve humanity's most profound problems, there is potentially great value in adding a perspective from modern evolutionary biology to those developing out of philosophy, the social sciences, religion, history and the humanities. This biological perspective must be added, not as an argument for determinism, but precisely to the contrary, as a possible way to greater freedom, deriving from greater knowledge of the cause-effect patterns that underlie our history and our nature. Some of my colleagues in biology, and many people outside biology, deny that humans can be understood in biological terms. Others cling to the notion that we evolved by an innocuous (and hypothetical) form of group selection and can somehow return to it. Or they argue that if this is not the case, we should deny the truth and pretend ourselves toward world peace and human justice; or that it is better to be ignorant with an idealized moral model before us than to know about an immoral history. I believe that people who think in these fashions are wrong. Worse, because of the enormity of the problems that face us, I regard approaches that deny biology, and sometimes deny reality, as potentially deadly. Essentially everyone thinks of himself as well-meaning, but from my viewpoint a society of well-meaning people who understand themselves and their history very well is a better milieu than a society of well-meaning people who do not. 